\title{
Putting Firms into Optimal Tax Theory
}

\author{
By Wojciech Kopczuk and Joel Slemrod*
}

Firms are, for the most part, absent from the modern theory of optimal taxation. Their disappearance dates from the foundational models developed by Peter A. Diamond and James A. Mirrlees (1971) in which firms are simply mechanical vehicles for combining productive inputs into output in cost-minimizing proportions. ${ }^{1}$

In contrast, firms play a central role in all modern tax systems, mostly for a reason stated by Richard M. Bird (1996): "The key to effective taxation is information, and the key to information in the modern economy is the corporation." In most countries, firms remit the majority of tax revenues to the government, either with regard to taxes legally owed by businesses or through withholding of taxes legally owed by employees or other businesses. ${ }^{2}$ Even when businesses are not required to remit taxes, they are often required to file information reports that can facilitate monitoring of tax liabilities.

The lack of a theoretical framework that features firms impedes rigorous welfare analysis of a number of important policy issues. One such example is the comparative evaluation of a uniform retail sales tax (RST) versus a value added tax (VAT). In the standard model, these two taxes-both remitted entirely by businessesare equivalent consumption taxes, but most experts consider the VAT to be clearly superior on administrative grounds, a view echoed in the

\footnotetext{
* Kopczuk, Economics Department, Columbia University, 1022 International Affairs Building, MC 3308, 420 West $118^{\text {th }}$ Street, New York, NY 10027 (e-mail: wkopczuk@nber.org); Slemrod, Stephen M. Ross School of Business, University of Michigan, 701 Tappan Street, Ann Arbor, MI 48109-1234 (e-mail: jslemrod@umich.edu). We thank Dhammika Dharmapala and Shlomo Yitzhaki for helpful comments on an earlier draft. Kopczuk acknowledges financial support from the Alfred P. Sloan Foundation.

${ }^{1}$ Diamond and Mirrlees (1971) proved that, under certain conditions, production efficiency is a necessary condition of an optimal tax system even when lump-sum transfers are not feasible.

${ }^{2}$ For example, over 80 percent of U.S. federal taxes are remitted by businesses, although only 10 percent are nominally business taxes.
}

recent report of the President's Advisory Panel on Federal Tax Reform (2005).

We propose a simple framework in which these and other issues can be analyzed. The new framework recognizes that a tax code must be backed up by an administrative and enforcement structure.

\section{Model Structure}

Although there are tax-specific aspects of enforcement, for all taxes the difficulty of enforcement depends on two features, both of which are related to why firms play a central role in tax systems: (a) "arm's-length" transactions, and (b) economies of scale. Transactions between unrelated, arm's-length parties, and information reports of these transactions, greatly facilitate enforcement. In contrast, the profits of firms flow from a firm to its owners and, therefore, are not subject to arm's-length information reports, so audits must suffice. ${ }^{3}$ One consequence of this is that the rate of noncompliance for taxes on the profits of the self-employed and other businesses is much higher than the rate for wages and salaries. ${ }^{4}$

The model we propose simply captures the essential elements of our story. In the oneperiod model economy, there are just two goods, where the technology of producing good 1 is given by $X_{1}=L_{1}$ and the technology of producing good 2 is given by $X_{2}=g\left(L_{2}, D\right)$, where $L_{i}$ represents the labor used in sector $i$ and $D$ is an intermediate input produced using the first technology. Thus, the output of technology 1 can be used as both the input in production of good 2 and as consumption good $C_{1}$, so that $X_{1}=C_{1}+D$ and $X_{2}=C_{2}$. We assume that markets for all inputs and outputs

\footnotetext{
${ }^{3}$ For public corporations, the information in financial statements provides some information to the authority.

${ }^{4}$ According to Alan Plumley (2004), in 1992 the net misreporting percentage for wage and salary income was 0.9 percent, compared to 31.8 percent for amounts subject to little or no information reporting-predominantly business income.
} 
are competitive, that both production functions exhibit constant returns to scale, and that a firm chooses to employ one technology or the other. (Vertical integration is addressed below.) We denote by $p$ the relative price of $C_{2}, w$ the pre-tax return to labor time, and $\pi$ the pre-tax profits. The economic profits are zero, but profits reported for tax purposes may be positive or negative, depending on tax incentives. ${ }^{5}$

The government needs to collect a fixed amount of revenue and can levy one or more of a set of linear taxes, but not lump-sum taxes. In particular, we model the RST, VAT, taxes on wages, and taxes on profits. To simplify the possible interactions among the taxes, we assume that a jurisdiction levies either an RST, a VAT, or some combination of wage and profit taxes; because wage taxes are withheld and remitted by firms, all tax revenue is remitted to the government by businesses. We restrict attention to the class of utility functions for which the relative price of goods 1 and 2, at the optimum, is undistorted. ${ }^{6}$ Ignoring administrative considerations, in this model this could be implemented equivalently either by a uniform RST, a uniform VAT, or a uniform tax on wages and profits (that are equal to zero).

Firms make decisions whether to comply with a particular kind of a tax. Noncompliance results in costs that we express in reduced form as $A(x)$ or $B(x)$, where $x$ is enforcement expenditure set by the government. In some cases, noncompliance requires the cooperation of two arm's-length parties; the cost of this kind of noncompliance is represented by $A(x)$. In other cases, noncompliance is a decision of a single agent; the cost of such noncompliance is denoted by $B(x)$. The costs of noncompliance may take many forms and involve things such as the

\footnotetext{
${ }^{5}$ If the true economic profit were always uniformly equal to zero, government would use this information to question any other reported value. Consider, however, a simple extension of the model to account for uncertainty that represents production as $X_{1}=L_{1}+\varepsilon_{1}$ and $X_{2}=g\left(L_{2}\right.$, $D)+\varepsilon_{2}$, respectively, where the $\varepsilon_{\iota}$ terms are mean zero. This would produce a distribution of firm profits with (assuming linear tax structures with full-loss offset) no changes to the behavior of risk-neutral firms, and therefore wouldn't affect our model except for breaking the equivalence between reporting profits and tax avoidance.

${ }^{6} \mathrm{We}$ also sidestep the possibility that, once administrative costs are introduced, it may be optimal to distort this relative price.
}

cost of restructuring transactions, hiring lawyers, investing in concealing activity from tax authorities, and foregoing opportunities that would increase the likelihood of detection or direct penalties. These costs are controllable by the government through the monetary expenditure $x$. We assume that it is much less costly to enforce taxes if the government can receive information reports from both sides of armslength transactions, which applies to businessto-business transactions of a VAT and to wage payments, but not to profits or (by assumption) to sales from businesses to consumers. Formally, we assume that $A(x)>B(x)$ and $A^{\prime}(x)>$ $B^{\prime}(x)>0$ - the same administrative investment results in higher overall and marginal private costs of noncompliance in the presence of monitorable arm's-length transactions.

A taxpayer either complies completely or does not comply at all. Given the potential tax liability of $T$ applying in an arm's-length context, the taxpayer involved will comply when $T \leq A(x)$, but not otherwise. Similarly, in the absence of arm's-length transactions, compliance will be guaranteed when $T \leq B(x)$. We consider policies that enforce taxes fully (and at minimal cost). ${ }^{7}$ Therefore, the cost of compliance in the case of an arm's-length relationship between parties is given by $a(x)=A^{-1}(T)$, and in the case of non-arm's-length transactions it is $b(x)=B^{-1}(T)$. Under full compliance, taxpayers effectively choose not to bear any private cost, which requires that the administrative expenses be present as means of deterrence. The total administrative costs are proportional to the number of effective entities that need to be monitored, either firms or, in the case of a wage tax, firms and employees. Holding the number of taxpayers constant and ignoring shifting across the tax bases, the administrative costs for each of the four taxes we consider can be written as follows:

- RST: $\varphi_{R}+b\left(t_{R} C_{1}\right) N_{1}+b\left(t_{R} p C_{2}\right) N_{2}$

- VAT: $\varphi_{V}+a_{F}(0) N_{1}+b\left(t_{V} C_{1}\right) N_{1}+$ $b\left(t_{V}\left(p C_{2}-D\right)\right) N_{2}$

\footnotetext{
${ }^{7}$ This assumption means that the social cost of evasion (or, later, income shifting) shows up not as the excess burden of revenue-lowering behavioral response but solely as administrative cost. A more general model would allow enforcement intensity to be chosen optimally.
} 
- Wage: $\varphi_{W}+a_{L}\left(t_{W} w L\right)\left(N_{1}+N_{2}+m N_{L}\right)$;

- Profit: $\varphi_{\pi}+b\left(t_{\pi} \pi\right)\left(N_{1}+N_{2}\right)$.

In these expressions, $N_{i}$ is the number of firms in sector $i$ and $N_{L}$ is the total number of employees. The $\varphi_{t}$ symbols refer to the fixed cost of having a given tax type at any rate.

According to this model, both wage payments and business-to-business sales generate monitorable arm's-length transactions. Although the RST is based on arm's-length sales, we assume that there is no practical way to involve the consumers in providing matchable information. The VAT has the same problem with matchable information reports for retail sales, but the tax base at risk is $C_{1}+p C_{2}-D$ (compared to $C_{1}+p C_{2}$ for the RST) as long as the government does not provide refunds to retail firms. With respect to business-to-business transactions $(D)$, where sales taxable to the seller are deductible inputs for the buyer, there is no tax savings under an invoice-credit system of not paying tax on a good sold to another business; this explains why zero is the argument of the $a_{F}$ function. We ignore the possibilities that firms fabricate invoices to render invisible the nonpayment of VAT and, under an RST, final consumers have an incentive to falsely claim to be (tax-exempt) business purchasers.

The second factor that affects the cost of raising revenue- and that differentiates across taxes-is the number of effective tax units that need to be monitored. We use the fixed factor $m(m<1)$ to translate the costs of dealing with an employee under a wage tax to that of dealing with a business, and use the $a_{F}$ and $a_{L}$ functions to differentiate the technologies required in monitoring business-to-business transactions and business-toemployee transactions, respectively. 8,9

Systems of raising revenue that are equivalent under the standard setup are no longer equivalent in this context. For example, while the proportional RST, VAT, and wage-and-

\footnotetext{
${ }^{8}$ Note that in this setup all firms are retail firms, although only some sell exclusively to consumers. In reality, the number of firms that have a retail business is significantly less than the total number of businesses, so that a retail sales tax requires that the tax administration deal with fewer tax units than under any of the other three taxes.

${ }^{9}$ For the sake of notational simplicity, we do not distinguish among the $b(\cdot)$ functions that apply to qualitatively different bases, although we recognize that the enforcement issues differ.
}

profits taxes are equivalent in a static context, their administrative costs are different. In particular, this simple model would imply that a VAT is less costly than an RST because the stakes in the retail sector are lower. It also highlights what factors are critical to evaluating the desirability of VAT over wage-and-profits taxation. While the tax base is the same and costly audits are used in either case, the tax stakes supported by audits are lower under profit taxation if profits are low. On the other hand, wage taxes, while easy to enforce due to their reliance on arm's-length transactions, involve many more parties. The key factors are therefore the relative cost of audits versus arm's-length monitoring and the relative number of parties involved.

To this point, we have not modeled behavioral responses that involve changing the number of (firm) taxpayers. But, consider that under a VAT, firms will organize to maximize the difficulty of enforcement at the retail level. This incentive would be present for the last two firms in a production chain acting jointly, for example, by vertically integrating. To illustrate the possible consequences in the context of our simple model, assume that $N_{1}=N_{2}=N$ and that one integrated firm results from merging one firm from each sector; complete vertical integration under a VAT would result in administrative costs of

$$
\text { VAT: } \varphi_{V}+b\left(t_{V} C_{1}+t_{V} p C_{2}\right) N
$$

where $N$ is the number of resulting firms. Comparing this expression to the earlier expression for the VAT reveals two differences. First, the overall tax that has to be enforced using nonarm's-length technology increases from $t_{V}\left(C_{1}+\right.$ $\left.\left(p C_{2}-D\right)\right)$ to $t_{V}\left(C_{1}+p C_{2}\right)$. Second, enforcement is now concentrated in a smaller number of businesses, with a higher tax stake per business. The first change represents an unambiguous loss to tax authorities (and therefore a social loss): part of tax revenue that was effectively self-enforced is no longer. As for the second effect, given our assumptions and additionally assuming convexity of $b(\cdot), \quad b\left(t_{V} C_{1}\right)+$ $b\left(t_{V}\left(p C_{2}-D\right)\right)<b\left(t_{V} C_{1}\right)+b\left(t_{V} p C_{2}\right)<$ $b\left(t_{V} C_{1}+t_{V} p C_{2}\right)$, and therefore it is more expensive to enforce taxes remitted by a vertically integrated firm. This is, of course, an assumption, but one with interesting economic content. The vertically integrated industry under either the VAT or RST is equally costly from the 
administrative point of view. Because the tax incentives to vertically integrate are stronger under the VAT than under the RST due to higher potential tax savings, an extension of the model that would relax vertical integration as an automatic tax winner could produce situations where VAT results in vertical integration, but RST does not, making the VAT a worse administrative option.

This reasoning implies that it is possible for production inefficiency to be part of an optimal solution, in contrast to the result in Diamond and Mirrlees (1971). This can occur under a VAT because of the lower cost of collecting revenue from business-to-business sales versus consumer sales. Indeed, any production benefits from vertical integration (not modeled here) may be offset by the negative administrative consequences of such integration due to the reduction of monitorable business-to-business transactions. This reasoning suggests that the equilibrium boundary of the firm may not be the socially optimal boundary, because what is efficient from a private perspective may complicate tax collection.

This reasoning can be usefully restated using the terminology of the marginal efficiency cost of funds (MECF) as developed in Slemrod and Shlomo Yitzhaki (1996). At an optimum, each tax system instrument used must have an identical MECF. But the term "instrument" needs to be defined more precisely than, say, "a tax of rate $t$ on commodity 1 " and, for example, needs to differentiate an RST from a VAT. If an RST is more difficult to enforce than a VAT, it will have a higher MECF. This is because (ignoring compliance costs) the MECF equals $X /(M R(1-$ $H)$ ), where $X$ is the marginal revenue absent any behavioral response, $M R$ is actual marginal revenue with behavioral response, and $H$ is the marginal administrative cost, here (as in our model) assumed to be proportional to revenue. If, ceteris paribus, $H$ is higher for an RST compared to a VAT, then its MECF is higher.

The revenue consequences of the incentive to integrate vertically will be accounted for in the calculation of $M R$ for a VAT. In the DiamondMirrlees framework, if all commodity taxes are available, the MECF of a tax that disturbs production efficiency will always be higher than the common MECF of each optimally set commodity tax. But in a world with administrative costs, this need not be the case. For example, a production-inefficient tax on large retail enterprises under a VAT might have a low MECF, because it has a low value of $H$-it saves on administrative costs relative to other taxes. The existence of this margin of response increases the MECF of the VAT, either because it increases the marginal "leakage" of revenue (i.e., $M R=X-M L$, where $M L$ is marginal leakage) or, in our framework, it increases $H$. Taking the appropriate policy action to address this margin of response ensures that the VAT generates its optimal MECF.

Our argument suggests that optimal policy, considering administrative cost externalities, may involve instruments that violate the standard notion of production efficiency. ${ }^{10} \mathrm{~A}$ related point has been made in the context of environmental externalities by Lans Bovenberg and Lawrence Goulder (1996), who showed that polluting intermediate inputs should be subject to taxation. In our context, administrative concerns alone could justify taxes or subsidies of bases or activities other than consumption, wages, or profits to the extent that they "pollute" or "clean" the tax system due to their administrative implications.

\section{Conclusions}

Many tax policy choices revolve around administration and enforcement issues, for which firms and firm-to-firm transactions are critical, and which cannot be informed by the kind of theoretical underpinning that Diamond and Mirrlees (1971) introduced in the early 1970s. We offer the model of this paper as a springboard for thinking about an alternative underpinning and argue that any such model must recognize the administrative efficiency advantages of businessbased tax remittance, monitorable arm's-length transactions, and economies of scale.

We highlighted three dimensions on which models with tax enforcement differ from the more standard optimal tax analysis. First, the budget-constraint-based equivalences among taxes on consumption and taxes on income and profits break down. Second, firms are critical in the tax system because they give rise to

\footnotetext{
${ }^{10}$ Walter P. Heller and Karl Shell (1974) introduced an alternative notion of production efficiency by redefining the production possibilities frontier to account for administrative costs.
} 
relatively easy-to-monitor transactions and can minimize the number of private agents the tax authorities must deal with. Third, certain behavioral responses that matter in this context have not yet been adequately addressed in the public finance literature, such as the size of, and boundaries between, firms, as well as incomeshifting responses across different bases.

\section{REFERENCES}

Bird, Richard M. "Why Tax Corporations?" Department of Finance Canada, Technical Committee on Business Taxation Working Papers: No. 1996-02, 1996.

Bovenberg, A. Lans and Goulder, Lawrence $\mathbf{H}$. "Optimal Environmental Taxation in the Presence of Other Taxes: General-Equilibrium Analyses." American Economic Review, 1996, 86(4), pp. 985-1000.
Diamond, Peter A. and Mirrlees, James A. "Optimal Taxation and Public Production I: Production Efficiency." American Economic Review, 1971, 61(1), pp. 8-27.

Heller, Walter P. and Shell, Karl. "On Optimal Taxation with Costly Administration." American Economic Review, 1974 (Papers and Proceedings), 64(2), pp. 338-45.

Plumley, Alan. Overview of the federal tax gap. Washington, DC: U.S. Department of the Treasury, Internal Revenue Service, NHQ Office of Research, 2004.

President's Advisory Panel on Federal Tax Reform. Simple, fair, and pro-growth: Proposal to fix America's tax system. Washington, DC: U.S. Government Printing Office, 2005.

-Slemrod, Joel and Yitzhaki, Shlomo. "The Costs of Taxation and the Marginal Efficiency Cost of Funds." International Monetary Fund Staff Papers, 1996, 43(1), pp. 172-98. 